\title{
Status Gizi dan Perkembangan Motorik Halus Anak Usia 48 - 60 Bulan
}

\author{
Analysis of Nutritional Status with Fine Motoric Development Children \\ Age 48-60 Months \\ Prasetyowati Prasetyowati ${ }^{1, 凶}$ \\ ${ }^{1}$ Jurusan Kebidanan, Politeknik Kesehatan Tanjung Karang, Indonesia \\ $\bowtie$ Corresponding author:w4ty_pras@yahoo.co.id
}

Kata kunci:
Perkembangan motorik
halus,
Status gizi anak usia $48-60$
bulan

Keyword:

Fine motor development, Nutritional status of children aged $48-60$ months

\begin{abstract}
Abstrak
Latar belakang: Perkembangan motorik halus pada bayi dan anak usia dini merupakan hal yang sangat penting. Gangguan koordinasi motorik diketahui diderita 1 dari 20 anak usia sekolah. Tujuan: Penelitian bertujuan menggambarkan status gizi dan perkembangan motorik halus anak usia 48-60 bulan murid kelas A PAUD Pertiwi Kota Metro. Methods: Penelitian ini menggunakan rancangan deskrifitif untuk menggambarkan status gizi dan perkembangan motorik halus anak usia 48-60 bulan. Populasi penelitian adalah murid kelas A PAUD Pertiwi Kota Metro dengan jumlah sampel 50 orang. Teknik pengambilan sampel menggunakan accidental sampling. Hasil: Hasil penelitian menunjukkan gambaran sejumlah $12 \%$ anak dengan status gizi kurus, ada $6 \%$ anak dengan perkembangan motorik normal. Terdapat anak dengan status gizi normal sejumlah 93,2\% dengan perkembangan motorik halus normal. Simpulan: Penelitian menyimpulkan status gizi anak ada kecenderungan mendukung perkembangan motorik halus anak usia $48-60$. Perlu kerjasama pihak sekolah dengan orang tua untuk melakukan pemantauan status gizi dan perkembangan motorik anak secara rutin agar anak dapat melewati setiap tugas perkembangan sesuai usianya.
\end{abstract}

\begin{abstract}
Background: Fine motor development in infants and young children is very important. Impaired motor coordination is known to affect 1 in 20 schoolaged children. Objective: The study aims to describe the nutritional status and fine motor development of children aged 48-60 months in grade A students of PAUD Pertiwi Metro City. Methods: This study uses a descriptive design to describe the nutritional status and fine motor development of children aged 48-60 months. The study population was students of class A PAUD Pertiwi Metro City with a sample of 50 people. The sampling technique uses accidental sampling. Results: The results showed a picture of $12 \%$ of children with underweight nutritional status, there were $6 \%$ of children with normal motor development. There are children with normal nutritional status of 93.2\% with normal fine motor development. Conclusion: The study concluded that the nutritional status of children has a tendency to support fine motor development in children aged 48 - 60. It is necessary for the school to collaborate with parents to monitor children's nutritional status and motor development routinely so that children can pass each developmental task according to their age.
\end{abstract}

Copyright $(2018$ Jurnal Kesehatan Metro Sai Wawai. All rights reserved. 


\section{Pendahuluan}

Masa balita merupakan periode emas (golden period) karena pada masa ini terjadi proses pertumbuhan dan perkembangan yang sangat cepat dan akan mempengaruhi dan menentukan pertumbuhan dan perkembangan anak selanjutnya. Proses tumbuh kembang terjadi secara kontinnyu dan saling bergantung satu sama lain (Almatsier, 2009). Kedua proses ini perlu dipantau secara teratur, sehingga bila ada keterlambatan proses tumbuh kembang dapat segera diketahui dan dilakukan tindakan.

Ranah perkembangan anak terdiri atas motorik kasar, motorik halus, bahasa / bicara, dan personal sosial / kemandirian. Perkembangan motorik halus pada bayi dan anak usia dini merupakan hal yang sangat penting. Anak belajar mengkoordinasikan tangan dan mata dengan baik agar dapat menggerakkan mainan. Gangguan motorik dalam fungsi motorik halus dapat berimplikasi pada munculnya hambatan belajar, hambatan mobilisasi, hambatan dalam aspek ekonomis produktif serta kelainan fungsi sosial dan psikologis (Dinkes Kota Metro, 2014). Seorang anak dapat mengalami keterlambatan perkembangan di hanya satu ranah perkembangan saja, atau dapat pula di lebih dari satu ranah perkembangan. Sekitar 5 hingga $10 \%$ anak diperkirakan mengalami keterlambatan perkembangan. Data angka kejadian keterlambatan perkembangan umum belum diketahui dengan pasti, namun diperkirakan sekitar 1-3\% anak di bawah usia 5 tahun mengalami keterlambatan perkembangan umum (Gella, 2013).

Gangguan koordinasi motorik diketahui diderita 1 dari 20 anak usia sekolah. Keterampilan gerakan merupakan dasar dari keterampilan belajar sehingga dengan adanya keterbatasan atau gangguan keterampilan gerak, seperti pada kasus gangguan keterampilan motorik maka masalah akan meningkat dan meluas seiring dengan bertambahnya usia anak. Kewaspadaan mengenai keadaan ini baru meningkat akhir-akhir ini berdasarkan bukti bahwa prevalensnya sekitar 5\% dari anak sekolah usia primer.Jika tidak ditangani, anak-anak dengan gangguan koordinasi motorik cenderung memiliki gejala yang bertahan pada masa remaja hingga masa dewasa (Ikatan Dokter Anak Indonesia, 2015).

Faktor-faktor yang mempengaruhi perkembangan motorik halus anak antara lain faktor kesehatan dan gizi. Status gizi merupakan salah satu faktor lingkungan yang dapat mempengaruhi perkembangan anak, karena untuk melakukan suatu aktivitas motorik, dibutuhkan ketersediaan energi yang cukup banyak (Dinkes Kota Metro, 2014). Anak yang kurang gizi biasanya selalu terlambat dalam perkembangan motoriknya. Anak yang kurang gizi menyebabkan turunnya fungsi otak sehingga menyebabkan kemampuan anak bereaksi terhadap rangsangan dari lingkungan sangat rendah dan anak menjadi apatis. Secara keseluruhan gizi buruk yang terjadi padak balita dapat membawa dampak anak mudah lelah dan sukar berkonsentrasi (Kaplan, Sadock \& Grebb, 2002). Anak-anak yang terlalu gemuk dan berat tubuh melebihi berat normal, akan mengalami hambatan mengikuti aturan main. Anak-anak yang terlalu tinggi atau gemuk bila dibandingkan dengan temannya seringkali menampilkan perilaku yang canggung dan lamban. Hal ini membuat mereka selalu berhati-hati dan terlalu sadar akan kekurangan dirinya. Kegemukan dapat membahayakan kesehatan yang dapat berakibat penyakit jantung, diabetes, dan tekanan darah tinggi.

Perkembangan motorik sangat dipengaruhi oleh gizi, status kesehatan, dan perlakuan gerak yang sesuai dengan masa perkembangannya. Secara anatomis, perkembangan akan terjadi pada struktur tubuh individu yang berubah secara proporsional seiring dengan bertambah usia seseorang. Status gizi yang kurang akan menghambat laju perkembangan yang dialami individu, akibatnya proporsi struktur tubuh menjadi tidak sesuai dengan usianya yang pada akhirnya semua itu akan berimplikasi pada perkembangan aspek lain (Kasenda, 2015).

Beberapa penelitian yang menerangkan tentang kaitan antara gizi dengan perkembangan motorik halus yaitu penelitian di PAUD Cilandak Jakarta Selatan. Faktor status gizi baik meningkatkan 5,7 kali kemampuan perkembangan motorik halus anak usia pra sekolah dibandingakan dengan status gizi anak tidak baik (Lindawati, 2013). Penelitian pada anak usia pra sekolah di TK GMIM Solafide 
Kelurahan Uner Kecamatan Kawangkoan Induk Kabupaten Minahasa memperoleh hasil ada hubungan antara status gizi dengan perkembangan motorik halus (Madiyaningtyas, 2015).

Di Indonesia prevalensi gizi kurang pada balita (BB/U) mengalami peningkatan 17,9\% dari 2010 dan menjadi 19,9\% tahun 2013. Di kota Metro jumlah kasus gizi buruk fluktuatif, tahun 2011 terdapat 3 kasus dan tahun 2012 naik kembali menjadi 7 kasus. Tahun 2013 dan 2014 dengan 4 kasus (Dinkes Kota Metro, 2014). Hasil studi pendahuluan yang dilakukan di TK Pertiwi dari 10 anak terdapat 1 orang (10\%) dengan status gizi lebih dan 1 orang (10\%) dengan status gizi kurus. Untuk itu, pengasuhan anak dengan stimulasi perkembangan anak yang optimal sangat diperlukan. Oleh karena itu, penelitian ini bertujuan memperoleh deskripsi status gizi dan perkembangan motorik halus anak. Selanjutnya, agar dapat dianalisis keterkaitan status gizi dan perkembangan motorik halus pada anak.

\section{Metode}

Penelitian ini menggunakan rancangan deskrifitif untuk menggambarkan status gizi dan perkembangan motorik halus anak usia 48-60 bulan. Populasi penelitian adalah murid kelas A PAUD Pertiwi Kota Metro dengan jumlah sampel 50 orang yang merupakan total populasi. Teknik pengambilan sampel menggunakan accidental sampling.

Pengumpulan data untuk memperoleh data variabel perkembangan motorik halus dan status gizi anak. Perkembangan motorik halus diukur dengan observasi menggunakan instrumen KPSP (kuesioner pra skrining perkembangan) dan alat permainan stimulasi tumbuh kembang anak umur 48-60 bulan. Status gizi anak dengan observasi menggunakan alat timbangan. Pengukuran perkembangan motorik halus dengan hasil dikotomi menggunakan kategori normal atau caution (peringatan), sedangkan status gizi anak dikategorikan normal $(\geq-2 \mathrm{SD})$ atau kurus $(<-2 \mathrm{SD})$.

Analisis data univariat dilakukan terhadap variabel status gizi dan perkembangan motorik kasar. Analisi univariat disajikan dengan persentase setiap variabelnya. Hasil analisi univariat disajikan dalam bentuk tabel distribusi frekuensi.

\section{Hasil}

\section{Karakteristik Responden}

Gambaran karakteristik responden terlihat dari jenis kelamin anak perempuan tidak jauh berbeda dengan anak laki-laki 28 orang $(54,9)$, sebagian besar anak lahir cukup bulan 44 orang (88\%). Anak dengan berat lahir normal ada 39 anak (78\%), dan anak yang BB nya turun karena sakit ada 4 orang (8\%). Terdapat 48 orang (96\%) anak mendapat stimulus (rangsangan) pada motorik halus. 38 orang (76\%) anak diasuh sendiri oleh orang tuanya dan 50 orang anak (100\%) anak diberikan kesempatan untuk bermain bersama teman sebayanya.

\section{Gambaran status gizi dan perkembangan motorik halus anak usia 48-60 bulan}

Gambaran status gizi anak usia 48-60 bulan pada tabel 1 memperlihatkan terdapat 44 anak (88\%) dengan status gizi normal, dan 6 anak (12\%) dengan status gizi kurus. Sedangkan, tabel 2 memperlihatkan gambaran bahwa terdapat 47 anak (94\%) dengan perkembangan motrorik normal, dan 3 anak (6\%) dengan perkembangan motorik halus caution. Sedangkan, tabel 3 memperlihatkan gambaran bahwa terdapat 47 anak (94\%) dengan perkembangan motrorik normal, dan 3 anak (6\%) dengan perkembangan motorik halus caution.

Tabel 3 menunjukkan dari 44 anak dengan status gizi normal terdapat 41 anak $(93,2 \%)$ dengan perkembangan motorik halus normal. Sedangkan, dari 6 anak dengan status gizi kurus terdapat 6 anak $(100 \%)$ dengan perkembangan motorik normal. 
Tabel 1.

Distribusi Status Gizi anak usia 48-60 bulan di PAUD Pertiwi Kota Metro

\begin{tabular}{lcc}
\hline \multicolumn{1}{r}{ Status Gizi } & $\mathbf{n = 5 0}$ & \% \\
\hline Normal & 44 & 88 \\
Kurus & 6 & 12 \\
\hline
\end{tabular}

Tabel 2.

Distribusi Frekuensi Perkembangan Motorik anak usia 48-60 bulan

\begin{tabular}{lcc}
\hline \multicolumn{1}{c}{ Motorik Halus } & $\mathbf{n = 5 0}$ & \% \\
\hline Normal & 47 & 94 \\
Caution/peringatan & 3 & 6 \\
\hline
\end{tabular}

Tabel 3.

Status gizi anak dan perkembangan motorik halus pada anak usia 48 - 60 Bulan

\begin{tabular}{lccccc}
\hline \multirow{2}{*}{ Status Gizi } & \multicolumn{4}{c}{ Perkembangan Motorik Halus } & \multirow{2}{*}{ Jumlah } \\
\cline { 2 - 4 } & \multicolumn{2}{c}{ Normal } & \multicolumn{2}{c}{ Caution } & \\
\cline { 2 - 5 } & $\mathbf{n}$ & $\boldsymbol{\%}$ & $\mathbf{n}$ & $\boldsymbol{\%}$ & 44 \\
\hline Normal & 41 & 93,2 & 3 & 6,8 & 6 \\
Kurus & 6 & 100 & 0 & 0 & 50 \\
Jumlah & 47 & 94 & 3 & 6 & \\
\hline
\end{tabular}

\section{Pembahasan}

\section{Status gizi anak usia 48-60 bulan}

Hasil analisis memperlihatkan anak dengan status gizi normal lebih tinggi dibanding kan dengan anak status gizi kurus (88\%). Hasil penelitian ini sejalan dengan penelitian di Puskesmas Miri Sragen, yaitu 93,5\% dengan status gizi normal (Mahendra \& Saputra, 2006). Status gizi adalah keadaan tubuh sebagai akibat konsumsi makanan dan penggunaan zat-zat gizi, yang diperoleh dari konsumsi makanan (Nugroho, Susanto \& Kartasurya). Gizi yang diperoleh seorang anak melalui konsumsi makanan setiap hari berperan besar dalam memenuhi kebutuhan gizi anak. Pada masa ini anak belum dapat menentukan/ memilih makanan yang baik, karena itu peran orang tua dalam menanamkan kebiasaan memilih makan yang baik menjadi sangat penting (Kaplan, Sadock \& Greb, 2002).

Hasil penelitian ini sebagian besar anak $88 \%$ dengan status gizi normal, ini dimungkinkan karena PAUD Pertiwi setiap hari mewajibkan anak untuk membawa bekal makanan untuk dimakan bersama saat jam istirahat. Makanan yang diperbolehkan dibawa adalah makanan yang memenuhi gizi seimbang. Melalui makan bersama anak diajarkan tata cara makan yang benar juga perilaku memilih makanan yang benar bagi dirinya. Anak juga dapat meniru kebiasaan makan temannya yang baik, karena pada masa ini anak masih senang sekali meniru. Taman kanak-kanak (TK) merupakan awal dari pengenalan anak dengan suatu lingkungan sosial. TK merupakan institusi yang disamping memberikan kesempatan bermain sambil belajar, juga mendidik anak untuk mandiri, bersosialisasi dan memperoleh berbagai keterampilan (Kaplan, Sadock \& Greb, 2002). Agar anak memperoleh asupan makan yang baik maka diperlukan kerjasama orang tua dan guru untuk membantu memilih dan memberikan makanan yang baik bagi anak didiknya dan membina serta mengawasi kesehatan anak.

Hasil penelitian lain terdapat 6 orang responden (12\%) dengan status gizi kurus. Berdasarkan data karakteristik responden didapatkan 4 orang anak $(8 \%)$ pernah sakit yang menyebabkan berat badannya turundan terdapat 7 anak (14\%) tidak rutin ditimbang setiap bulannya. Perlu upaya pemantauan kesehatan anak secara rutin, agar tidak berdampak terhadap pertumbuhan anak. 


\section{Perkembangan motorik halus anak usia 48-60 bulan}

Motorik halus merupakan gerakan yang hanya melibatkan bagian-bagian tubuh tertentu yang dilakukan oleh otot-otot kecil. Gambaran perkembangan motorik halus hasil penelitian ini menunjukkan 47 anak (94\%) dengan perkembangan motorik normal, dan 3 anak (6\%) dengan perkembangan motorik halus caution (peringatan). Hasil penelitian ini sejalan dengan penelitian di Puskesmas Miri Sragen, yaitu 56 anak (90,3\%) dengan perkembangan motorik halus normal (Mahendra \& Saputra, 2006).

Hasil penelitian ini sebagian besar anak dengan perkembangan motorik normal (94\%), kemungkinan karena rangsangan/stimulus yang diberikan oleh orang tua. Berdasarkan karakteristik responden terdapat 48 anak (96\%) diberikan stimulus oleh orang tuanya. Selain rangsangan 100\% orang tua menyatakan memberikan kesempatan anaknya untuk bermain dengan teman sebayanya.

Stimulus merupakan hal yang penting dalam tumbuh kembang anak. Stimulasi untuk memperkenalkan pengetahuan atau keterampilan baru sangat penting untuk anak. Anak yang mendapat stimulasi terarah dan teratur akan lebih cepat berkembang dibandingkan dengan anak yang kurang atau tidak mendapat stimulasi (Rudiyanto, 2016).

Hasil analisis penelitian terdapat 3 anak dengan perkembangan motorik halus dalam kategori caution/peringatan, dimungkinkan karena anak tidak diasuh sendiri oleh orang tuanya, sehingga memungkinkan anak kurang mendapat rangsangan dan perhatian yang cukup. Ada 12 anak (24\%) yang tidak diasuh secara penuh oleh orang tuanya, umumnya diasuh oleh pengasuh atau nenek. Perlu upaya pemberian stimulus untuk merangsang perkembangan motorik halus anak. Stimulasi yang diberikan disesuaikan dengan kebutuhan dan umur anak. Rangsangan dapat dilakukan sambil bermain dengan lingkungan yang kondusif dan anak diberi dukungan bila mengalami kesulitan. Perlu intervensi dini bagi anak dengan perkembangan motorik caution agar tidak mengarah pada keterlambatan perkembangan motorik halus.

Perkembangan motorik halus sangat dipengaruhi oleh organ otak. Otak mengatur setiap gerakan yang dilakukan anak. Semakin matang perkembangan sistem syaraf otak yang mengatur otot memungkinkan berkembangnya motorik anak Agar otak dapat berkembang secara maksimal dibutuhkan asupan energi, besi, seng tembaga, LC-PUFAs dan kolin yang adekuat, (Soetjiningsih, 1998). Faktor lain, yang dapat mempercepat perkembangan motorik halus anak yaitu, perkembangan sistem syaraf, kemampuan fisik yang memungkinkan untuk bergerak, adanya rangsangan dan prematurita (Dinkes Kota Metro, 2014). Karena perkembangan motorik dipengaruhi oleh banyak faktor, maka orang tua memegang peranan penting dalam proses pengembangan motorik halus anak. Kecerdasan motorik halus anak berbeda-beda dalam hal kekuatan maupun ketepatannya. perbedaan ini juga dipengaruhi oleh pembawaan anak dan stimulasi yang didapatkannya. Lingkungan (orang tua) mempunyai pengaruh yang lebih besar dalam kecerdasan motorik halus anak. Lingkungan dapat meningkatkan ataupun menurunkan taraf kecerdasan anak, terutama pada masa-masa pertama kehidupannya.

Perlu upaya setiap anak mampu mencapai tahap perkembangan motorik halus yang optimal dengan dukungan mendapatkan asupan gizi optimal dan stimulasi perkembangan anak dengan rutin dan tepat. Di setiap fase, anak membutuhkan rangsangan untuk mengembangkan kemampuan mental dan motorik halus anak.

\section{Simpulan dan saran}

Hasil penelitian menyimpulkan terdapat anak dengan status gizi normal sejumlah 93,2\% dengan perkembangan motorik halus normal. Ada kecenderungan status gizi anak baik mendukung perkembangan motorik halus anak usia $48-60$. Perlu upaya pemantauan tumbuh kembang anak secara rutin, agar anak dapat melewati setiap tugas anak perkembangan sesuai usianya. Penanganan yang tepat bagi anak yang mengalami perkembangan motorik halus caution/peringatan. 


\section{Referensi}

Almatsier, S. (2009). Prinsip dasar ilmu gizi. Jakarta: Gramedia Pustaka Utama.

Dinkes Kota Metro. (2014). Profil kesehatan Metro Tahun 2013.

Gella, N. d. (2013). Analsis perbedaan perkembangan antara anak balita gizi baik dengan gizi kurang (Studi di Kelurahan Karang Siri Kota Soe Tahun 2012). Majalah Kesehatan Masyarakat. 7(1).

Ikatan Dokter Anak Indonesia. (2015). Keterlambatan perkembangan pada anak. Retrieved from http://idai.or.id/public-articles/seputar-kesehatan-anak/mengenal-keterlambatan-perkembangan-umumpada-anak.html.

Kaplan, H. I., Sadock, B. J., \& Greb, J. A. (2002). Sinopsis psikiatri ilmu pengetahuan psikiatris klinis (Vol. 2). Jakarta: Binarupa Akasara.

Kasenda, M. d. (2015). Hubungan Status Gizi dengan Perkembangan Motorik Halus pada Anak Usia Prasekolah di TK GMIM Solsfide Kelurahan Uner Kecamatan Kawangkoan Kabupaten Minahasa. Jurnal Keperawatan (e-kp), 3(1). 1-8

Lindawati. (2013). Faktor-faktor yang berhubungan dengan perkembangan motorik anak prasekolah. Jurnal Helath Quality. 4(1), 1-76.

Madiyaningtyas, E. (2015). Hubungan status gizi dengan perkembangan motorik halus anak usia 3-5 tahun di Puskesmas Miri Kabupaten Sragen. Skripsi. Stikes Kusuma Husada Surakarta

Mahendra, A., \& Saputra, Y. (2006). Perkembangan belajar motorik Departemen Pendidikan Nasional. Jakarta: Universitas Terbuka.

Moehyl, S. (2003). Ilmu gizi: penanggulangan gizi buruk. Jakarta: Bhratara Niaga Medis.

Nugroho, A., Susanto, H. \& Kartasurya, M. I. (2014). Pengaruh mikronutrian taburia terhadap perkembangan motorik anak usia 24-48 bulan yang stunting. Jurnal Gizi Indonesia (ISSN) (1858-4942), 3(1). 52-59. Doi: https://doi.org/10.14710/jgi.3.1.141-145

Rudiyanto, A. (2016). Perkembangan motorik kasar dan motorik halus anak usia dini. Darussalam PRESS

Santoso, S. (1999). Kesehatan dan Gizi. Jakarta: Rineka Cipta.

Soetjiningsih. (1998). Tumbuh Kembang Anak. Jakarta: EGC. 